https://doi.org/10.37208/tgn27304

\section{Behaviour of a lone female honey- buzzard on breeding grounds in central Scotland}

\author{
C.J. McInerny ${ }^{1} \&$ K.D. Shaw ${ }^{2}$ \\ ${ }^{1}$ School of Life Sciences, University of Glasgow, \\ Glasgow G12 8QQ \\ ${ }^{2} 13$ Chalmers Brae, Anstruther, Fife KY10 3BY \\ ${ }^{1}$ E-mail: chris.mcinerny @glasgow.ac.uk
}

The honey-buzzard (Pernis apivorus) is a rare and elusive breeder in Scotland (McInerny \& Shaw, 2019). We have been monitoring the species in central Scotland for the past 30 years and studying it intensely since 2008 (McInerny \& Shaw, 2018). Our work has been largely based on field observations of birds, but in recent years we have combined this with nest studies using camera traps. We work closely with Forestry and Land Scotland (FLS) and hold disturbance licences for honey-buzzard in the area and beyond.

An essential part of the project is identifying occupied territories and potential breeding pairs. The process of establishing breeding pairs and nest locations is complicated by non-breeding birds which can be present in higher numbers than breeders (Clements, 2005; Shaw et al., 2017; McInerny et al., 2018a).

The first active nest that we located was in east central Scotland during 2018. The male of this pair was known to us from previous years and named by us as "Shorty". He was pale grey in colour, in our experience the most common colour form of honey-buzzard observed in central Scotland (Shaw et al., 2019). By mid-May he was usually one of the first birds to return to the breeding areas and was visible throughout the season, often interacting with other males. The female of this pair was thought to be "Bournville", named by us due to her dark brown plumage (McInerny et al., 2018a; McInerny et al., 2018b). This, however, was never established conclusively, as she was extremely difficult to observe; two other females were also seen close to the nest during 2018.

Late in the 2018 breeding season we found the nest in the crown of a very mature Douglas fir (Pseudotsuga menziesii) that had been planted during 1974 (FLS pers. comm.) in thick, established, coniferous woodland, close to an old ride. This tree position was inconvenient for camera traps but our partners in the project, FLS, placed one on a nearby tree. The pair successfully reared two young that were photographed on the nest (McInerny et al., 2018b). No adults were seen in the nest images, probably because it was late in the season.
Two cameras were placed in trees next to this same nest in early May 2019 before the arrival of birds. Soon after the breeding season started it was suspected that Shorty had not returned. Furthermore, a pair of common buzzards (Buteo buteo) had moved closer to the honeybuzzard's nest that we had located, perhaps resulting in the pair moving elsewhere nearby. We searched the surrounding area for the new nest without success, although an active nest in an adjacent territory of honeybuzzards named by us as "Turnberry" and "Whiteshaft" was discovered that produced two young, with a camera trap installed that recorded these (McInerny et al., 2020). A third unused nest was discovered in another territory on 31st July, most likely the 2017 nest used by the pair named by us as "Shakespeare" and "Anne" (McInerny et al., 2018a).

When all the honey-buzzards had left the area at the end of the breeding season, FLS retrieved the cameras in mid-October. It was only then that we understood the breeding outcome during 2019 of the Douglas fir nest. A female honey-buzzard, not previously known to us, returned to the nest on 16th May. Such an early arrival date for a female suggests that she was an older bird returning to a previously used nest on an established territory. She remained on the nest intermittently for several days but did not lay a fresh branch until 25th May; honey-buzzards routinely refurbish their old nests, usually with greenery and new sticks (Hardey et al., 2013; McInerny et al., 2020). Following this there was an active period of nest building with more fresh branches added from 27th to 29th May (Figs. 1, 2), after which she was not seen again. Interestingly, no male honey-buzzard was observed at the nest all season, and so it seems likely that the female departed having not found a mate. The nest was, however, visited by other bird species and mammals after the female honeybuzzard had left: a young female northern goshawk (Accipiter gentilis) (8th June), jays (Garrulus glandarius), wood pigeons (Columba palumbus), red squirrels (Sciurus vulgaris), and a pine marten (Martes martes) (G. Mason, pers. comm.). Jays were recorded visiting while the female honey-buzzard was on the nest, at times mobbing her (Fig. 2).

The 2019 breeding season, unlike the previous four years, was challenging for honey-buzzards in central Scotland, with fewer pairs and non-breeders. Our visual observations and the camera trap images indicate that Shorty and probably Bournville did not return to the study area. Honey-buzzard populations in the north of the U.K. are thought to be less stable than populations in the south (R. Clements, pers. com.) resulting in fluctuations in numbers. Such fluctuations reflect the observation that the species is a long-distance migrant from Africa. At least during 2019 the reduced numbers were unlikely due to food shortages of the main prey items which are wasp larvae (Hymenoptera) and amphibians, as the other nest in the adjacent territory 
was well supplied, with the pair rearing two young (McInerny et al., 2020).

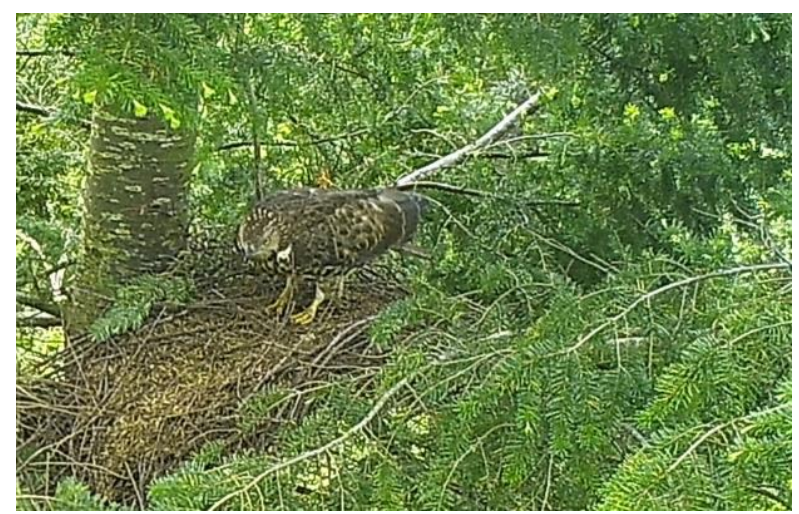

Fig. 1. Female honey-buzzard (Pernis apivorus), central Scotland, 27th May 2019. By this date she had deposited just one fresh branch on the nest. (Photo: G. Mason, C. French \& M. Rafferty)

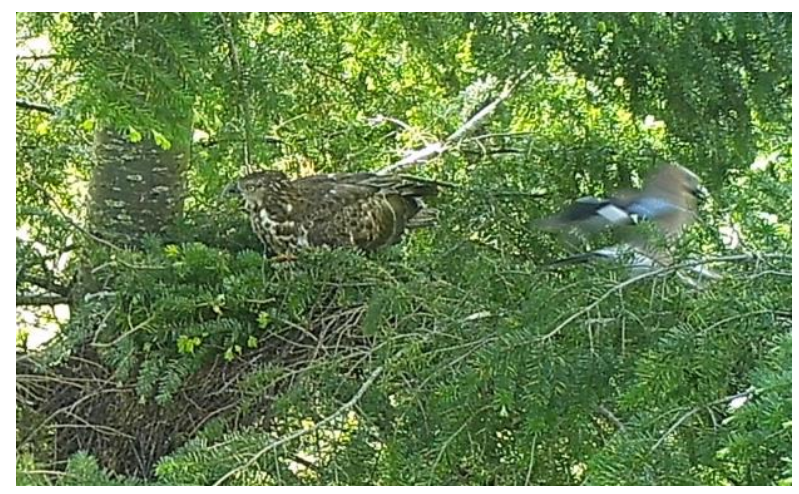

Fig. 2. Female honey-buzzard (Pernis apivorus), central Scotland, 28th May 2019. By the following day, she had placed a number of fresh branches on the nest. Note the flying jay (Garrulus glandarius), which had been mobbing her. (Photo: G. Mason, C. French \& M. Rafferty)

A combination of detailed observations and camera trap images reveal a fascinating insight into honey-buzzard nesting biology, which is little understood on British breeding grounds. Two cameras in nearby trees are an advantage. Cameras should be installed in early May and set to last until mid-September. Many honeybuzzard nests in conifers are extremely difficult to find being placed in one of two positions: in the crown, or high up next to the trunk (Hardey et al., 2013). The latter are more convenient for camera positioning. Finally, it is important to emphasise that all work should be carried out under licence, and with the landowner's permission.

We thank G. Mason and C. French (Forestry and Land Scotland), and M. Rafferty (Central Scotland Raptor Study Group) for installing and operating the camera trap. We are grateful to Ali Little and Kenny Little who, along with KDS and Forestry and Land Scotland staff carried out most of the nest searching. We thank a reviewer for improvements to the text. To support the 2019 work CJMcI received a grant from the Glasgow Natural History Society, Professor Blodwen Lloyd Binns Bequest; and KDS received a grant from the
Scottish Ornithologists' Club.

\section{REFERENCES}

Clements, R. (2005). Honey-buzzards in Britain. British Birds 98, 153-155.

Hardey, J., Crick, H., Wernham, C., Riley, H., Etheridge, B. \& Thompson, D. (2013). Raptors: a Field Guide for Surveys and Monitoring. (3rd edition). The Stationery Office (TSO), Scotland.

McInerny, C.J. \& Shaw, K.D. (2018). Observations on the 'wing-clapping' aerial display of honey-buzzards in central Scotland. British Birds 111, 226-227.

McInerny, C.J. \& Shaw, K.D. (2019). The honeybuzzard in Scotland: a rare, secretive and elusive summer visitor and breeder. The Glasgow Naturalist 27(1), 20-26. https://doi.org/10.37208/tgn27103

McInerny, C.J., Shaw, K.D., Little, A., Little, K., Hoey, K., Gibb, K. \& Kerr, B. (2018a). Honey-buzzards in central Scotland: observations and comparisons from two study areas during 2017. Scottish Birds 38, 15-29.

McInerny, C.J., Shaw, K.D., Hoey, K., Little, A., Little, K., Gibb, K. et al. (2018b). Honey-buzzards in central Scotland during 2018 - a different breeding year. Scottish Birds 38, 308-313.

McInerny, C.J., Shaw, K.D., Mason, G., Little, A. \& Little, K. (2020). Observations on nesting honeybuzzards in central Scotland during 2019. Scottish Birds 40, 72-75.

Shaw, K.D., McInerny, C.J., Little, A., Little, K., Nadin, J.S. \& Goater, R. (2017). An exceptional season at a central Scotland honey-buzzard study area. Scottish Birds 37, 3-13.

Shaw, K.D., McInerny, C.J., Gibb, K. \& Hoey, K. (2019). Identification of honey-buzzards on Scottish breeding grounds. Scottish Birds 39, 68-74. 